\title{
EDITORIAL
}

\section{Should we be concerned about the durability of percutaneous aortic valves?}

\section{¿Deberíamos preocuparnos por la durabilidad de las válvulas aórticas percutáneas?}

\author{
Darío Echeverri ${ }^{\mathrm{a}, \mathrm{b}, \mathrm{c}, *}$, Partho P. Sengupta ${ }^{\mathrm{d}, \mathrm{e}}$, Pedro R. Moreno ${ }^{\mathrm{f}, \mathrm{g}}$
}

\author{
a Department of Hemodynamics and Cardiovascular Inverventionism, Fundación Cardioinfantil - Instituto de Cardiología, Bogotá, \\ Colombia \\ b Vascular Function Research Laboratory, Fundación Cardioinfantil - Instituto de Cardiología, Bogotá, Colombia \\ c Medical College, Universidad del Rosario, Bogotá, Colombia \\ 'Cardiac Ultrasound Research at The Mount Sinai Medical Center, New York, USA \\ e Medicine and Cardiology at The Mount Sinai Medical Center, New York, USA \\ ${ }^{f}$ Icahn School of Medicine at Mount Sinai, New York, USA \\ s Cardiac Catheterization Laboratory and Interventional Cardiology Mount Sinai Saint Luke's Hospital, New York, USA
}

Received 8 February 2017; accepted 9 February 2017

Available online 15 March 2017

Transcatheter aortic valve replacement is an excellent treatment option for patients with severe symptomatic aortic stenosis and high or intermediate surgical risk. Based on solid scientific evidence obtained from randomized clinical studies, why would it be important to consider the durability of these valves, and why has this concern just now been made public?

The long-term durability of valves used in transcatheter aortic valve replacement has been of interest based on various factors. Ongoing technological development reduces the procedural risks and improves life expectancy. Transcatheter aortic valve replacement is increasingly being used in young patients, even those with congenital pathologies such as bicuspid aortic valves. Even in more complex pathologies

DOI of original article:

http://dx.doi.org/10.1016/j.rccar.2017.02.003

* Corresponding author.

E-mail address: decheverri@cardioinfantil.org (D. Echeverri). including dysfunctional bioprostheses with severe stenosis or regurgitation, a procedure known as valve-in-valve. ${ }^{1,2}$ However, in spite of the ever increasing penetration of the technique, a large population with severe symptomatic aortic stenosis, who could be potential candidates for transcatheter aortic valve replacement, remains undiagnosed and untreated.

Technology today has advanced greatly, allowing a smaller valve and delivery system profile, production using better materials (hydrophilic), developments in tissue preservation techniques $\left(3^{\text {rd }}\right.$ and $4^{\text {th }}$ generation), recapturable designs and thinner materials used in manufacturing the valve (thickness of percutaneous valve leaflets $\approx 0.25 \mathrm{~mm}$ compared to $\approx 0.4 \mathrm{~mm}$ leaflets in surgical valves). These conditions help to explain the greater use and availability of more than 25 percutaneous valves in the global market. ${ }^{3,4}$

In spite of the excellent clinical evaluation of survival, the long-term hemodynamic evaluation is only evolving. Group analyses mask individual changes in mean gradients, 
and could be subject to bias. Furthermore, findings of valve leaflet immobility or in-situ thrombi are only detectable with careful transesophageal echocardiogram or 4D cardiac tomography techniques.

In 2012, the Valve Academic Research Consortium2 Consensus, ${ }^{5}$ drafted a document which attempted to describe for the first time, the criteria for identifying structural deterioration of transcatheter implanted valves. Criteria such as mean aortic valve gradient $\geq 20 \mathrm{~mm}$ $\mathrm{Hg}$, effective valve opening area $\leq 0.9 \mathrm{~cm}^{2}$, moderate or severe prosthetic valve regurgitation with a regurgitant volume $>30 \mathrm{ml}$, regurgitant fraction $>30 \%$ and effective regurgitant orifice area $>0.10 \mathrm{~cm}^{2}$, along with the need to repeat the procedure (percutaneous valve implantation or surgical valve replacement), were considered.

One of the first clinical registries of transcatheter aortic replacement patient follow-up was published in $2013,{ }^{6}$ consolidating the results of five years following implantation of the Cribier-Edwards and Edwards SAPIEN valves in 88 patients in Canada. A mean gradient post-transcatheter aortic valve replacement of $10.0 \pm 4.5 \mathrm{~mm} \mathrm{Hg}$ was achieved, along with a post-transcatheter aortic valve replacement aortic valve area of $1.67 \pm 0.41 \mathrm{~cm}^{2}$. It was interesting to note that at five yearsí follow-up, a small percentage of patients developed moderate or severe aortic valve regurgitation. Furthermore, the five year report of the PARTNER 1 study in patients with severe aortic stenosis and high surgical risk, ${ }^{7}$ as well as in patients with inoperable aortic stenosis, ${ }^{8}$ did not report signs of structural valve deterioration, according to the Consensus definition. In 2015, Barbanti et al. ${ }^{9}$ issued the results of a five year follow-up of 353 patients who had undergone third generation Core Valve (Medtronic Inc, Minneapolis, Minnesota) implantation in 18 Italian centers. They described severe, late prosthetic failure in 5 cases (1.4\%). Two patients required valve-in-valve implants due to symptomatic restenosis, one case of endocarditis with severe aortic regurgitation, one case of severe structural valve deterioration, and one with severe paravalvular leak. In ten additional patients $(2.8 \%)$, late mild aortic stenosis was documented, with a mean transvalvular gradient of 20-40 mm Hg.

Furthermore, in an exhaustive analysis ${ }^{10}$ carried out to identify the clinical results and durability of transcatheter valves, with more than two years of follow-up in 23 analyzed articles, only one case of early pseudo-degeneration of the valve with thrombosis at six months, and eight reports of structural valve deterioration were described; five of them with CoreValve (Medtronic Inc, Minneapolis, Minnesota), and three with Edwards SAPIEN. No patients developed severe aortic regurgitation or stenosis, or required surgery or reintervention. More recently, results were presented during the TCT2016 in Washington, of a two year follow-up of patients after implantation of the Evolut R (Medtronic Inc, Minneapolis, Minnesota) valve. Sixty patients with follow-up at 30 days, one, and two years, reported $0 \%$ embolization or migration, $0 \%$ endocarditis, $0 \%$ valve dysfunction requiring new procedures, and $0 \%$ valve thrombosis.

All these results had the scientific community at ease with regard to the durability of the valves. However, in 2016 there were new findings, and new concepts were defined.

Del trigo et al. ${ }^{11}$ sought to determine the incidence, the timing and the predictors of valve hemodynamic deterioration (VHD), using a multicenter registry which included 1,521 patients who underwent transcatheter aortic valve replacement; $48 \%$ of them were male, with an average age of $80 \pm 7$ years. A transthoracic echocardiogram was performed at discharge, at six and 12 months, and then yearly. VHD was defined as $a \geq 10 \mathrm{~mm} \mathrm{Hg}$ increase in the transvalvular gradient. This study identified the predictors of VHD following transcatheter aortic valve replacement, including: lack of anticoagulant therapy at discharge, valvein-valve procedures, transcatheter valve diameter $\leq 23 \mathrm{~mm}$, and higher body mass index. This study now considers the possibility of anticoagulation following transcatheter aortic valve replacement, especially those patients with valve-invalve, small valve diameters, and obesity.

Possible causes of structural deterioration of percutaneous valves may include native valve calcification and some technical aspects in the preparation of the valve to be implanted. The severity, extent and distribution of native valve contributes to the is responsible for the distortion of the implanted valve. This will lead to inappropriate placement, oblique implantation, incomplete expansion, increased mechanical tension in the leaflets, and paravalvular leaks. ${ }^{12-15}$

The tissue used for transcatheter aortic valve replacement is similar to that of the surgical valve (bovine or porcine pericardium), and the anticalcification treatment used is equivalent to that of surgical valves. However, the reasons for which the durability of surgical and percutaneous valves may be different are related to the need to reduce the profile of the system, using thinner materials; in addition, crimping the leaflets may cause microscopic tissue damage. In the United States, studies have been performed on computational models of tissue fatigue ${ }^{4}$ to compare the durability of transcatheter aortic valve replacement vs. surgical bioprosthetic valves under optimal conditions, and the durability of the transcatheter aortic valve replacement devices compared with surgical valves has been shown to be reduced to $\approx 7.8$ years; it is expected that this durability will be even further reduced under less than optimal conditions (elliptical anatomy, or sub-expanded implant). Likewise, crimping, implantation and balloon dilation of percutaneous valves may cause various degrees of lesions, deformations and tears in the collagenous structure of the pericardial leaflets of the implanted valves, which promotes platelet adhesion and capture, and exacerbates thrombogenicity, supporting the growing reasoning that long-term durability of the biofunctionality of percutaneous implantation valves is questionable. ${ }^{16}$

In general, bioprosthetic valves are less thrombogenic than mechanical valves. However, SVD may occur due to a decreased mobility of the leaflets, resulting in thrombosis. According to previous studies of surgical valves, an incidence of valvular thrombosis close to $1 \%$ is expected. Using high resolution multidetector $\mathrm{CT}$, the incidence of thromboses in transcatheter aortic valve implantation of up to $7 \%$ at three months, which could have relevant implications. Hansson et al. ${ }^{17}$ evaluated the incidence, predictors, and clinical implications of transcatheter aortic implant thromboses, using multidetector CT in 460 consecutive patients undergoing Edwards Sapien XT or Sapien 3 (Edwards Lifesciences, Irvine, California) transcatheter aortic valve replacement. Thickening, hypoattenuation of the leaflets, suggestive of 


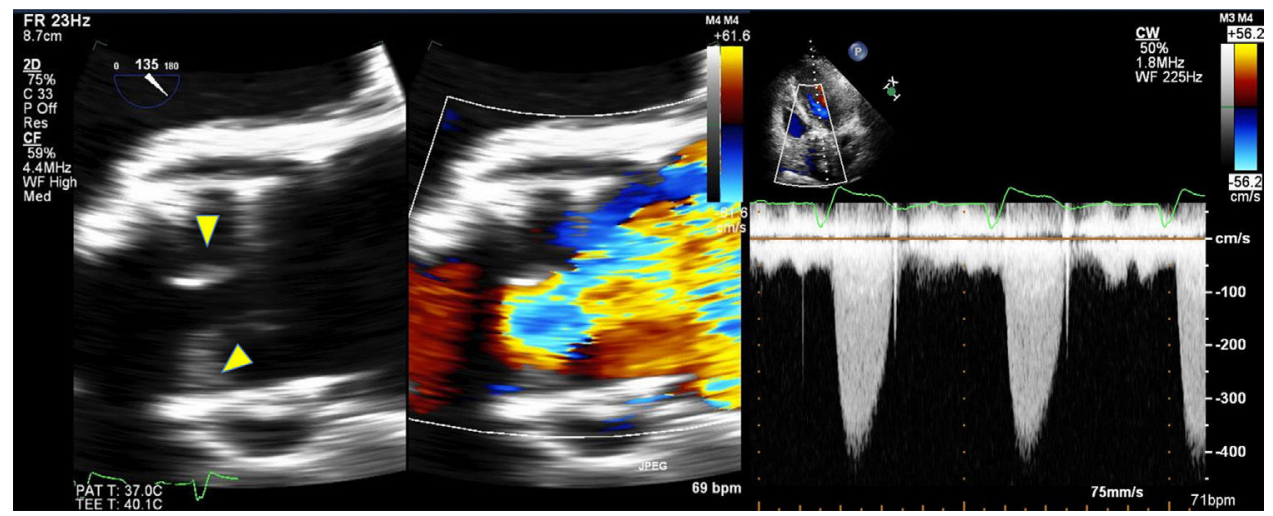

Figure Thickening and mobility restriction of the valve leaflets following transcatheter aortic valve replacement (Edwards Lifesciences, Irvine, California) with severe aortic stenosis.

thrombosis, even without signs of obstruction on transthoracic echocardiogram (TTE) was seen in 405 (88\%) patients who underwent CT and transesophageal echocargiogram (TEE) 1-3 months after transcatheter aortic valve replacement (mean gradient (MG): $9 \mathrm{~mm} \mathrm{Hg}$, valve opening area: $\left.1.6 \mathrm{~cm}^{2}\right)$, and complete resolution of the thrombus after three months of treatment with warfarin and aspirin. High resolution multidetector $\mathrm{CT}$ revealed transcatheter aortic valve thrombosis in 28 out of 405 patients (7\%): 23 patients with subclinical thrombosis, and $5(18 \%)$ with obstructive thrombosis. Thrombosis of the percutaneous aortic valve was the same within the different generations of valves ( $8 \%$ vs. $6 \%, p=0.42)$. Thrombosis of the transcatheter aortic valve was greater in those who did not receive warfarin than in those who receive it $(10.7 \%$ vs. $1.8 \%$, RR: 6.09 ; 95\% Cl: 1.86 - 19.84). Based on these findings, some SVD and transcatheter aortic valve thrombosis factors coincide, such as the lack of anticoagulation with warfarin, the increased transvalvular gradient, the increase in thickness of the cusps, anomalous mobility of the cusps, and the size of the valve used (needs confirmation) (Figure).

In conclusion, solid long-term durability data of transcatheter aortic valves are only available for a maximum of five years. Experience with surgical aortic valves shows that more than ten years of follow-up of older patients are needed to properly analyze the durability of the valve. There is an inverse relationship between age and structural valve deterioration. Therefore, caution is required when considering transcatheter aortic valve replacement in low and intermediate risk, and young patients. The incidence of SVD and thrombosis is as yet unknown. It is important to monitor the transvalvular gradient (TEE); as was previously described. Patients with gradients $>10 \mathrm{~mm} \mathrm{Hg}$ will require CT evaluation to ruled out SVD and possible thrombosis. (value to be validated) Furthermore, oral anticoagulation may be indicated. It is still unclear whether antiplatelet therapy alone is sufficient or vitamin $\mathrm{K}$ antagonists are needed, or if a new oral anticoagulant should be added in the first three to six months. Ongoing studies include: GALILEO (the Global Study Comparing a rivAroxaban-based Antithrombotic Strategy to an antipLatelet-based Strategy After Transcatheter aortlc vaLve rEplacement to Optimize Clinical Outcomes), evaluates rivaroxaban versus DAPT; CLOE (Clopidogrel to Lower advErse ischemic events after trans- catheter aortic valve) (aspirin vs. dual antiplatelet therapy); and ATLANTIS (Anti-Thrombotic Strategy After Trans- Aortic Valve Implantation for Aortic Stenosis) (apixaban $5 \mathrm{mg} 2$ vs. dual antiplatelet therapy or vitamin $\mathrm{K}$ antagonist).

\section{Conflicto de intereses}

Los autores declaran no tener ningún conflicto de intereses.

\section{References}

1. Walther T, Hamm CW, Schuler G, Berkowitsch A, Kötting J, Mangner N, et al., GARY Executive Board. Perioperative results and complications in 15,964 transcatheter aortic valve replacements: prospective data from the GARY registry. JACC. 2015;65:2173-80.

2. Holmes DR Jr, Brennan JM, Rumsfeld JS, Dai D, O’Brien SM, Vemulapalli S, et al. STS/ACC TVT Registry. Clinical outcomes at 1 year following transcatheter aortic valve replacement. JAMA. 2015;313:1019-28.

3. Thubrikar MJ, Deck JD, Aouad J, Nolan SP. Role of mechanical stress in calcification of aortic bioprosthetic valves. J Thorac Cardiovasc Surg. 1983;86:115-25.

4. Martin C, Sun W. Comparison of transcatheter aortic valve and surgical bioprosthetic valve durability: A fatigue simulation study. J Biomech. 2015;48:3026-34.

5. Kappetein AP, Head SJ, Généreux P, Piazza N, van Mieghem NM, Blackstone EH, et al., Valve Academic Research Consortium-2. Updated standardized endpoint definitions for transcatheter aortic valve implantation: the Valve Academic Research Consortium-2 consensus document. Eurolntervention. 2012;8:782-95.

6. Toggweiler S, Humphries KH, Lee M, Binder RK, Moss RR, Freeman $\mathrm{M}$, et al. 5-year outcome after transcatheter aortic valve implantation. J Am Coll Cardiol. 2013;61:413-9.

7. Mack MJ, Leon MB, Smith CR, Miller DC, Moses JW, Tuzcu EM, et al., for the PARTNER 1 trial investigators. 5-year outcomes of transcatheter aortic valve replacement or surgical aortic valve replacement for high surgical risk patients with aortic stenosis (PARTNER 1): a randomised controlled trial. Lancet. 2015;385:2477-84.

8. Kapadia SR, Leon MB, Makkar RR, Tuzcu EM, Svensson LG, Kodali $\mathrm{S}$, et al., for the PARTNER trial investigators. 5-year outcomes of transcatheter aortic valve replacement compared with standard treatment for patients with inoperable aortic stenosis (PARTNER 1): a randomised controlled trial. Lancet. 2015;385:2485-91. 
9. Barbanti M, Petronio AS, Ettori F, Latib A, Bedogni F, De Marco F, et al. 5-year outcomes after transcatheter aortic valve implantation with corevalve prosthesis. JACC Cardiovasc Interv. 2015;8:1084-91.

10. Sulzenko J, Tousek P, Kocka V, Widimsky P. Transcatheter aortic valve implantation: long-term clinical outcome and valve durability. Expert Rev Med Devices. 2015:1-7.

11. Del Trigo M, Muñoz-Garcia AJ, Wijeysundera HC, NombelaFranco L, Cheema AN, Gutierrez E, et al. Incidence, timing, and predictors of valve hemodynamic deterioration after transcatheter aortic valve replacement: multicenter registry. J Am Coll Cardiol. 2016;67:644-55.

12. Hayashida K, Lefèvre T, Chevalier B, Hovasse T, Romano M, Garot P, et al. Impact of post-procedural aortic regurgitation on mortality after transcatheter aortic valve implantation. JACC Cardiovasc. Interv. 2012;5:1247-56.

13. Kodali SK, Williams MR, Smith CR, Svensson LG, Webb JG, Makkar RR, et al. PARTNER Trial Investigators. Two-year outcomes after transcatheter or surgical aortic-valve replacement. N Engl J Med. 2012;366:1686-95.
14. Tamburino C, Capodanno D, Ramondo A, Petronio AS, Ettori F, Santoro G, et al. Incidence and predictors of early and late mortality after transcatheter aortic valve implantation in 663 patients with severe aortic stenosis. Circulation. 2011;123:299-308.

15. Abdel-Wahab M, Zahn R, Horack M, Gerckens U, Schuler $\mathrm{G}$, Sievert $\mathrm{H}$, et al., German transcatheter aortic valve interventions registry investigators. Aortic regurgitation after transcatheter aortic valve implantation: incidence and early outcome. Results from the German transcatheter aortic valve interventions registry. Heart. 2011;97:899-906.

16. Bourget JM, Zegdi R, Lin J, Wawryko P, Merhi Y, Convelbo $\mathrm{C}$, et al. Correlation between structural changes and acute thrombogenicity in transcatheter pericardium valves after crimping and balloon deployment. J Morpho. 2016;282: $1-14$.

17. Hansson NC, Grove EL, Andersen HR, Leipsic J, Mathiassen ON, Jensen JM, et al. Transcatheter aortic valve thrombosis: incidence, predisposing factors, and clinical implications. J Am Coll Cardiol. 2016;68:2059-69. 